\title{
EVALUATION OF BREAST LESIONS WITH DOPPLER ULTRASOUND: DIAGNOSTIC ACCURACY OF RESISTIVE INDEX AS A PREDICTOR OF MALIGNANCY.
}

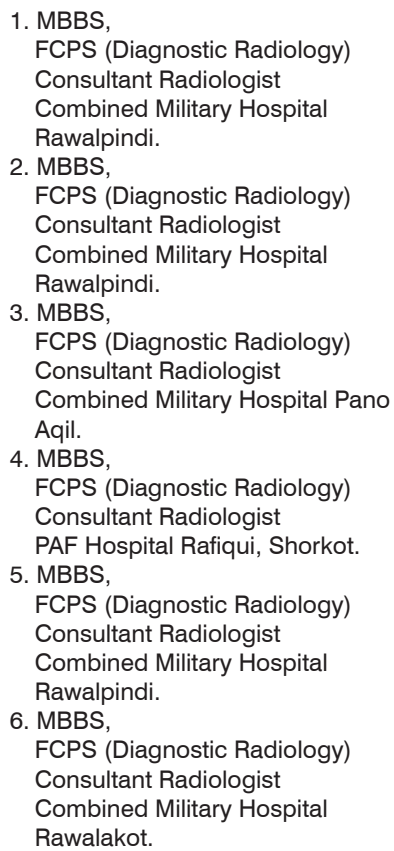

Correspondence Address:

Dr. Faran Nasrullah

Department of Radiology

Combined Military Hospital

Rawalpindi.

faran.nas@gmail.com

Article received on:

$17 / 07 / 2019$

Accepted for publication:

22/10/2019

\begin{abstract}
Ishrat Parveen ${ }^{1}$, Koukab Javed $^{2}$, Breeha Elahi ${ }^{3}$, Faran Nasrullah ${ }^{4}$, Rashid Mahmood ${ }^{5}$, Muhammad Omer Aamir ${ }^{6}$

ABSTRACT... Objectives: To evaluate breast lesions with doppler ultrasound and calculate the diagnostic accuracy of resistive index as a predictor of malignancy, taking histopathology as gold standard. Study Design: Cross-sectional study. Setting: Radiology Department, $\mathrm{CMH}$ Multan. Period: December 2015 to May 2016. Material \& Methods: 150 female patients, having age between $20-60$ years, with palpable breast lumps were admitted in the study. Doppler ultrasound of the lesion was performed with emphasis on the vascularity and resistive index was formulated. Categorization as malignant or otherwise was declared as established by doppler ultrasound. Patients then underwent biopsy followed by histopathology. Correlation of doppler ultrasound and histopathological findings was done with calculation of diagnostic accuracy of doppler ultrasound, keeping histopathology as gold standard. Results: The mean of age was $40.23 \pm 5.75$ years. In 81 breast doppler ultrasound positive patients, 73 (True Positive) showed malignant lesions in breast while 08 (False Positive) did not have malignancy on biopsy. Among 69 Breast Doppler Ultrasound negative patients, 06 (False Negative) demonstrated malignancy on biopsy whereas 63 (True Negative) did not have any malignant lesion. Overall specificity was $88.77 \%$, sensitivity $92.40 \%$, negative predictive value $91.30 \%$, positive predictive value $90.12 \%$ and diagnostic accuracy of Doppler Ultrasound came out 90.67\%. Conclusion: Angiogenesis in malignant lesions lead to formation of structurally abnormal and tortuous vessels with increased resistive index. Doppler ultrasound is a safe and effective modality which shows acceptable diagnostic accuracy for noninvasive characterization of malignant breast lesions. Therefore, it can be employed as an alternative to histopathology in patients who present with breast lesions.
\end{abstract}

Key words: Breast Carcinoma, Diagnostic Accuracy, Doppler Ultrasound, Histopathology, Resistive Index.

Article Citation: Parveen I, Javed K, Elahi B, Nasrullah F, Mahmood R, Aamir MO. Evaluation of breast lesions with Doppler ultrasound: Diagnostic accuracy of resistive index as a predictor of malignancy. Professional Med J 2020; 27(4):825830. DOI: 10.29309/TPMJ/2020.27.04.3947

\section{INTRODUCTION}

Breast lesion is described as an area within breast parenchyma that differs from the surrounding breast tissue in appearance or consistency. It may vary in size from a small nodule to a large mass occupying almost the entire breast. Breast lump is the commonest symptoms of breast related disease with increasing number of patients reporting to the female OPD with this dilemma. Breast lumps may result from a number of reasons, broadly divided into benign and malignant causes, with majority of them being benign, such as fibrocystic disease, fibroadenoma, breast abscess or mastitis. ${ }^{1}$ Fibroadenoma is the commonest cause of benign breast lump. ${ }^{2}$
Breast cancer comes second as the most frequent cancer worldwide (more than 1.6 million cases) and 5th most fatal malignancy $(0.5$ million, $6.4 \%) .{ }^{3}$ Pakistan is a high risk area with regards to breast cancer ${ }^{4}$ and its prevalence in Karachi is the highest in Asia. ${ }^{5}$ Earlier it used to be considered a disease afflicting the older middle aged females; however its incidence is on the rise in younger population nowadays. ${ }^{6}$ Even with major publicity and increasing awareness regarding breast carcinoma, there is a delay in seeking health care in Pakistan, with $88.8 \%$ patients presenting late (more than 03 months) and $59 \%$ presenting at an advanced stage (Stage III /IV). ${ }^{7}$ 
Ultrasonography is a non-invasive, widely available, affordable and easy to perform imaging modality, which is free from ionizing radiations, and can be used safely even in pregnant females. It can diagnose of breast lesions with specificity of $57 \%$ and diagnostic accuracy of ultrasound $80 \%{ }^{8}$ However, as it is highly operator dependant, the quality assurance becomes more challenging due to human variability with the limitation that third parties are unable to scrutinize an earlier examination apart from the data and images provided by the operator. $^{9}$

Doppler ultrasound works on the principle that frequency of a pulse from moving particle is altered, giving Doppler frequency, depending on its speed with respect to its origin. ${ }^{10}$ Thus, it can be used provides information regarding the blood flow in the vessels, the direction of flow and velocities around and inside breast lesions. Resistive index is an estimate of resistance offered by vessels to the flowing blood. Cancerous growths release vascular growth factors, which promote development of newer vessels. ${ }^{11}$ However these vessels are tortuous with an abnormal structure, resulting in increased resistance to blood. Thus, doppler ultrasound of malignant masses reveals a higher Resistance Index (RI) as compared to benign growths or normal tissue. Thus, using these features, doppler ultrasound can be used to characterize breast masses in to benign or malignant. Malignant lesions also have features such as central vascularity, hypervascularity or tortuous vessels while benign lesions are predominantly usually have normal or reduced number of vessels. ${ }^{11}$

Histopathology is contemplated as investigation of choice to ascertain the nature of pathology, differentiation of benign from malignant tumors and determination of tumor grade. ${ }^{12}$ However, apart from being invasive, it may result in an array of potential unpleasant side effects like bleeding, infection or damage to adjacent nerves, vessels and viscera. Furthermore, it can result in seeding of the tumor cells along the biopsy track, leading to metastatic spread. Another limitation is the inadequate availability of trained specialists who perform and interpret this procedure.
Aim of conducting this research study is to establish doppler ultrasound as an accurate investigation for reliable characterization of breast masses. Not much research has been performed in Pakistan on this topic. A few studies have been conducted internationally but have yielded contrasting results. Once proved, doppler ultrasound can be used accurately to segregate patients that would require further biopsy and histopathology. This would result in a decline in the number of unnecessary biopsies, causing less unwanted complications and also reducing the burden on our health system.

\section{METHODOLOGY}

This cross-sectional study was conducted in Radiology Department, $\mathrm{CMH}$ Multan, from $1^{\text {st }}$ December 2015 to $30^{\text {th }}$ May 2016. 150 patients meeting the inclusion criteria were evaluated. Sample size was calculated with $95 \%$ confidence level, taking expected prevalence of breast cancer as $47 \%{ }^{13}$ with sensitivity of $91.6 \%{ }^{14}$ and specificity $84.6 \%{ }^{14}$ of Doppler ultrasound in diagnosing malignant breast lesions. Permission was taken from the ethical review committee of the hospital.

Female patients, having age 20 - 60 years, diagnosed with breast lumps, participated in the study. Patients with diagnosed breast lesions, previous breast biopsy or surgery were not included in the study. Each patient was made clear the objective and written consent was obtained. Using a high- frequency linear probe, ultrasonography of the affected breast was performed. Doppler ultrasound of the lesion was carried out and the resistive index was computed $(\mathrm{RI}=$ peak systolic velocity - end diastolic velocity / peak systolic velocity). Each lesion was characterized as malignant or otherwise on the verdict of resistive index calculated. Feature suggestive of malignancy was Resistive Index (RI) more than or equal to 0.70 while a RI less than 0.70 favored a benign lesion. The results were kept secret. Biopsy followed by histopathological examination was carried out. Doppler ultrasound findings were compared with histopathology to establish the diagnostic accuracy.

Analysis of data was done through SPSS 22. 


\section{RESULTS}

The mean of age was $40.23 \pm 5.75$ years while the range of age was 22 to 59 years. Most of the patients incorporated in the study were in the 40 to 49 age group. Mean duration of disease was $13.23 \pm 3.85$ months. Mean size of lump was 4.83 $\pm 2.35 \mathrm{~cm}$. Mean BMI was $29.74 \pm 5.35 \mathrm{~kg} / \mathrm{m}^{2}$.

All the patients were subjected to Doppler Ultrasound. In 81 (54.0\%) patients Doppler Ultrasound favored the diagnosis of malignant breast lesions. In $83(52.67 \%)$ cases histopathology confirmed the diagnosis of malignancy. In 81 breast doppler ultrasound positive patients, 73 (True Posi- tive) showed malignant lesions in breast while 08 (False Positive) did not have malignancy on biopsy. Among 69 Breast Doppler Ultrasound negative patients, 06 (False Negative) demonstrated malignancy on biopsy whereas 63 (True Negative) did not have any malignant lesion. Overall specificity was $88.77 \%$, sensitivity was $92.40 \%$, negative predictive value was $91.30 \%$, positive predictive value was $90.12 \%$ while diagnostic accuracy of Doppler Ultrasound in characterizing lesions of breast was $90.67 \%$ as shown in Table-I. Characteristics of benign and malignant tumor are shown in Table-II.

\begin{tabular}{|c|c|c|c|c|c|c|c|c|c|c|}
\hline \multirow{2}{*}{\multicolumn{2}{|c|}{ Doppler Ultrasound }} & \multicolumn{9}{|c|}{ Histopathology } \\
\hline & & \multicolumn{4}{|c|}{ Positive } & \multicolumn{5}{|c|}{ Negative } \\
\hline \multicolumn{3}{|l|}{ Positive } & \multicolumn{3}{|c|}{$\begin{array}{c}73 \\
\text { (True Positive) }\end{array}$} & \multicolumn{5}{|c|}{$\begin{array}{c}08 \\
\text { (False Positive) }\end{array}$} \\
\hline \multicolumn{2}{|l|}{ Negative } & & \multicolumn{3}{|c|}{$\begin{array}{c}06 \\
\text { (False Negative) }\end{array}$} & \multicolumn{5}{|c|}{$\begin{array}{c}63 \\
\text { (True Negative) }\end{array}$} \\
\hline \multicolumn{11}{|c|}{$\begin{array}{c}\text { Table-I. Calculation of diagnostic accuracy } \\
\text { Sensitivity: TP } /(\text { TP }+ \text { FN }) \times 100=92.40 \% \text {, Specificity: TN } /(T N+F P) \times 100=88.77 \% \text {, Positive predictive value: TP } / \\
\text { TP+ FP } \times 100=90.12 \%, \text { Negative predictive value: TN } / \text { FN }+ \text { TN } \times 100=91.30 \% \text {, Accuracy: TP+ TN } / \text { TP+FP+FN+TN x } \\
100=90.67 \%\end{array}$} \\
\hline \multirow{2}{*}{$\begin{array}{l}\text { Diagnosis (Histo- } \\
\text { Pathology) }\end{array}$} & \multicolumn{4}{|c|}{ Age (Yrs) } & \multicolumn{3}{|c|}{ BMI } & \multicolumn{3}{|c|}{ Size of Lesion $(\mathrm{cm})$} \\
\hline & 20 to 29 & 30 to 39 & 40 to 49 & 50 to 59 & $\downarrow 18.5$ & $18.5-24.9$ & $\uparrow 25$ & $\leq 1$ & $1-2$ & $\geq 2$ \\
\hline Benign & 17 & 20 & 18 & 12 & 12 & 21 & 34 & 13 & 21 & 33 \\
\hline Malignant & 04 & 17 & 39 & 23 & 21 & 29 & 33 & 19 & 29 & 35 \\
\hline
\end{tabular}

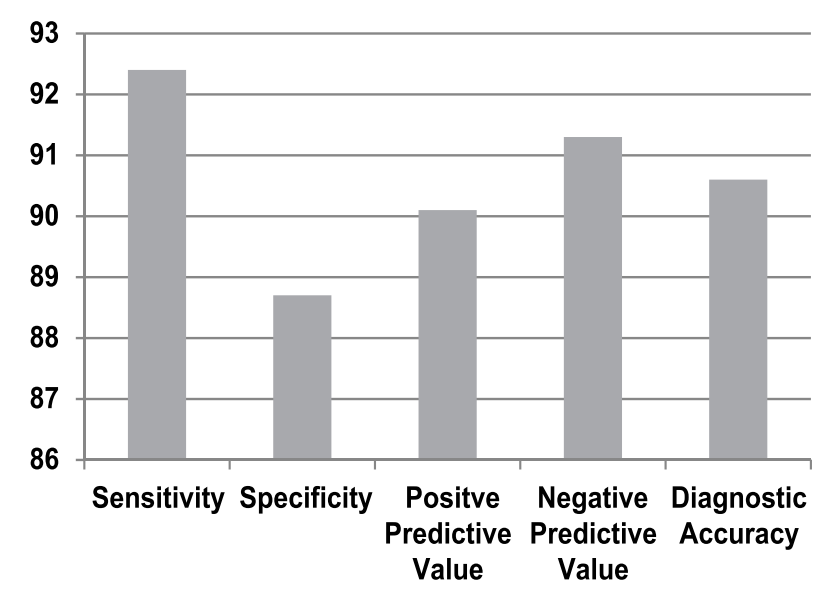

Figure-1. Sensitivity, Specificity, PPV, NPV and Diagnostic Accuracy of Doppler ultrasound

\section{DISCUSSION}

Breast carcinoma is extremely notorious, being the most prevalent and lethal carcinoma in females globally. ${ }^{15}$ Almost one woman in every eight will suffer from it in her lifetime while it will prove to be fatal in one in 30 women. ${ }^{16}$ The role on a radiologist in patients with breast lumps is accurate differentiation of benign and malignant cases. This will not only comfort the patients with benign lesions but also result in early identification of the malignant cases, which will be of paramount importance in favorable prognosis of disease.

Doppler ultrasound utilizes the change in vascularity as the discriminating feature of malignancies. In our study, sensitivity was $92.40 \%$, 


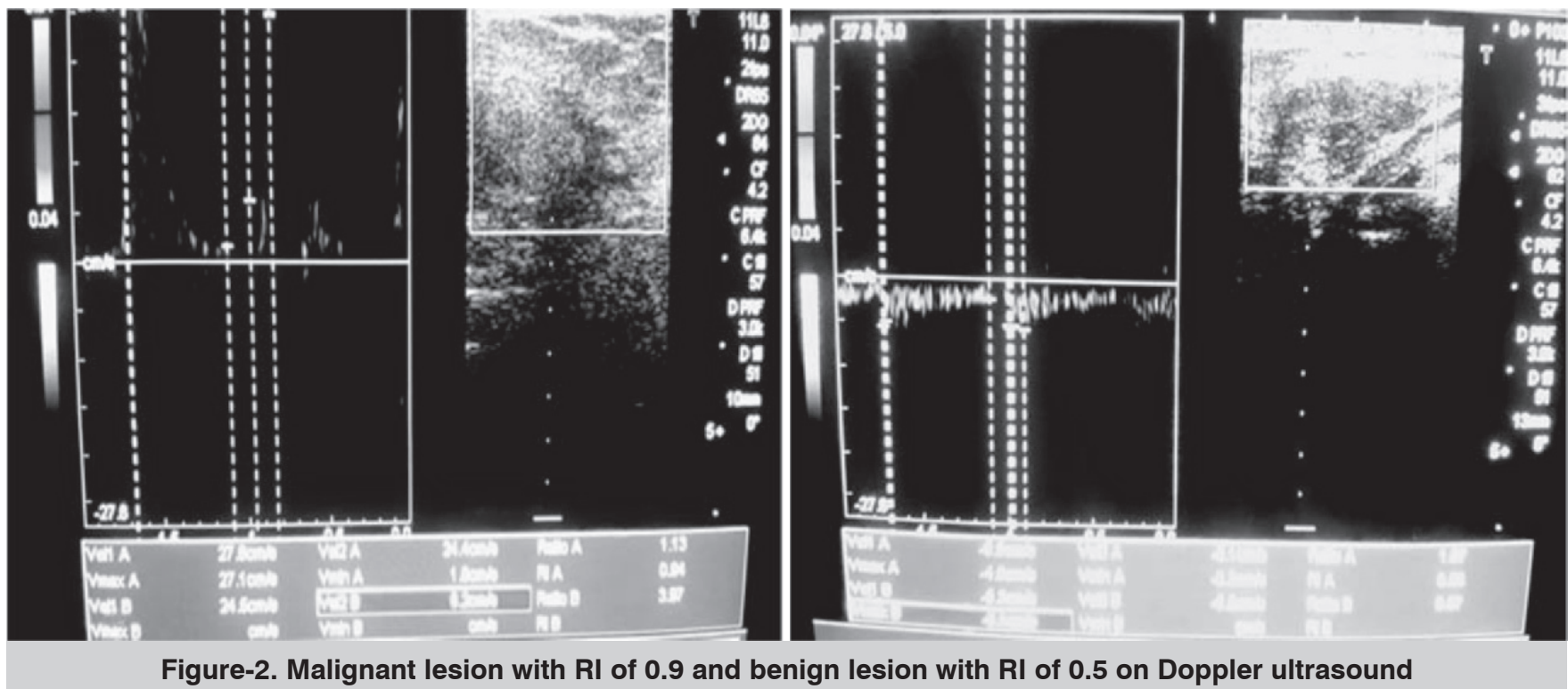

specificity was $88.77 \%$, positive predictive value (PPV) was 90.12\%, negative predictive value (NPV) was $91.30 \%$ while diagnostic accuracy was calculated as $90.67 \%$. Only limited studies are found using doppler ultrasound alone for diagnosis of malignant breast lesions based on the $\mathrm{Rl}$ values. del Sirous $\mathrm{M}$ et $\mathrm{al}^{17}$ evaluated the role of doppler ultrasound in characterization of breast masses and concluded that resistive index (RI) value showed sensitivity of $75 \%$ and high specificity of $97 \%$ for diagnosing breast carcinoma at a threshold value of 0.83

Cura JL et-al ${ }^{18}$ performed a study regarding application of doppler ultrasound for assessment of breast masses. The study shows that any breast mass may be established as malignant, if there is a vessel having $\mathrm{Rl}$ value more than 0.99 inside, irrespective of other ultrasound features.

Choi HY et $\mathrm{al}^{19}$ organized research regarding the role of doppler ultrasound in discrimination of benign from malignant breast masses. They formulated that mean of $\mathrm{Rl}$ seen in benign breast masses was $0.62+/-0.095$ (range 0.44-0.86) while that for malignant lesions was $0.74+/$ 0.097 (range, 0.50-0.92). The value of resistive index was more than 0.7 in about $80 \%$ cases of malignancies. The difference of the RI proved to be significant statistically for threshold value of $0.7(P<0.001)$ and resistive index exceeding 0.7 , signified a malignant lesion.

Recent innovations in breast ultrasound, such as elastography, contrast enhanced ultrasonography and automated whole-breast ultrasound, are newer avenues that need to be explored. Elastography is a newer procedure that assesses the extent of elasticity of breast tissue and differentiates lesions into benign or malignant based on these findings. ${ }^{20}$ Contrastenhanced ultrasound is an innovative modality producing quantifiable measures of vascularity that could assist in evaluation of breast lesions. ${ }^{21}$ Automated whole breast US is a recent technique that allows acquisition of a volumetric threedimensional breast dataset and shows promising results in accurate characterization of breast masses. ${ }^{22}$ However more studies are needed to validate these techniques.

The number of studies using resistive index as the discriminating criteria for breast lesions are scarce. The effort to find any national study on this topic was futile. Few international studies, mentioned above, were found and were consistent with our results.

\section{CONCLUSION}

Angiogenesis in malignant lesions lead to formation of structurally abnormal and tortuous vessels with increased resistive index. Doppler 
ultrasound is a safe and effective modality which shows acceptable diagnostic accuracy for noninvasive characterization of malignant breast lesions. Therefore, it can be employed as an alternative to histopathology in patients who present with breast lesions. Consequently, there will be a decline in morbidity and complications caused by biopsies as well as reduced burden on the health delivery system.

\section{CONFLICT OF INTEREST}

Nil

\section{Copyright(C) 22 Oct, 2019.}

\section{REFERENCES}

1. Sharma A, Ali S, Devendra S. Breast lump in a patient with Type 1 Diabetes. London Journal of Primary Care. 2016; 8(3):42-5.

2. Tahir S, Ahmad S, Jain RC. Clinicopathological and radiological evaluation of benign breast diseases - A comparison between FNAC and core biopsy. J. Evolution Med. Dent. Sci. 2016; 5(94):6936-9.

3. Ferlay J, Soerjomataram I, Dikshit R, Eser S, Mathers $\mathrm{C}$, Rebelo $\mathrm{M}$, et al. Cancer incidence and mortality worldwide: sources, methods and major patterns in GLOBOCAN 2012. Int $J$ Cancer. 2015 Mar 1; 136(5):E359-86.

4. Jamal S, Mamoon N, Moghal S, Mushtaq S, Luqman M. Carcinoma breast: A histopathological audit. J Coll Physicians Surg Pak. 2006 Feb; 16(2):117-9.

5. Bhurgri Y. Karachi cancer registry data--implications for the national cancer control program of Pakistan. Asian Pac J Cancer Prev. 2004 Jan-Mar; 5(1):77-82.

6. Basra MA, Saher M, Athar MM, Raza MH. Breast cancer in Pakistan a critical appraisal of the situation regarding female health and where the nation stands? Asian Pac J Cancer Prev. 2016; 17(7):3035-41.

7. Gulzar F. Identifying the barriers of delayed presentation in Pakistani breast cancer patients undergoing Care at Tertiary Hospital. Journal of Global Oncology. 2018; (4_suppl_2):215s-215s.

8. Slebi HA, Sarsam SD, Marzook AA. Evaluation of breast lumps in women aged 18-40 years. Research \& Reviews: Journal of Oncology and Hematology. 2019; $8(1): 5-9$.
9. Evans A, Trimboli RM, Athanasiou A, Balleyguier $\mathrm{C}$, Baltzer PA, Bick $U$, et al. Breast ultrasound: recommendations for information to women and referring physicians by the European Society of Breast Imaging. Insights Imaging. 2018 Aug; 9(4):449461.

10. Jenderka KV, Delorme S. Principles of Doppler sonography. Radiologe. 2015 Jul; 55(7):593-609.

11. Stanzani D, Chala LF, Barros Nd, Cerri GG, Chammas MC. Can Doppler or contrast-enhanced ultrasound analysis add diagnostically important information about the nature of breast lesions? Clinics (Sao Paulo). 2014 Feb; 69(2):87-92.

12. Tadayyon H, Sadeghi-Naini A, Wirtzfeld L, Wright F, Czarnota G. Quantitative ultrasound characterization of locally advanced breast cancer by estimation of its scatterer properties. Medical Physics. 2014; 41(1):012903.

13. Devolli-Disha E, Manxhuka-Kerliu S, Ymeri H, Kutllovci A. Comparative accuracy of mammography and ultrasound in women with breast symptoms according to age and breast density. Bosnian J Basic Med Sci. 2009; 9(2):131-6.

14. Nadeem A, Ahmad MW, Ahmad A. Role of colour doppler sonography in the diagnosis of breast Tumors. Pak J Med Health Sci 2011; 5(3):589-91.

15. Akram M, Iqbal M, Daniyal M, Khan AU. Awareness and current knowledge of breast cancer. Biol Res. 2017 Oct 2; 50(1):33.

16. Siegel RL, Miller KD, Jemal A. Cancer statistics, 2016. CA Cancer J Clin. 2016 Jan-Feb; 66(1):7-30.

17. Sirous M, Sirous R, Nejad FK, Rabeie E, Mansouri M. Evaluation of different aspects of power Doppler sonography in differentiating and prognostication of breast masses. J Res Med Sci. 2015 Feb; 20(2):133-9.

18. del Cura JL, Elizagaray E, Zabala R, Legórburu A, Grande D. The use of unenhanced Doppler sonography in the evaluation of solid breast lesions. AJR Am J Roentgenol. 2005 Jun; 184(6):1788-94.

19. Choi HY, Kim HY, Baek SY, Kang BC, Lee SW. Significance of resistive index in color Doppler ultrasonogram: Differentiation between benign and malignant breast masses. Clin Imaging. 1999 SepOct; 23(5):284-8.

20. Botticelli A, Mazzotti E, Di Stefano D, Petrocelli V, Mazzuca F, La Torre M. Positive impact of elastography in breast cancer diagnosis: an institutional experience. J Ultrasound. 2015 Aug 12; 18(4):321-7. 
21. Sridharan A, Eisenbrey JR, Dave JK, Forsberg F. Quantitative Nonlinear Contrast-Enhanced Ultrasound of the Breast. AJR Am J Roentgenol. 2016 Aug; 207(2):274-81.
22. Meng Z, Chen C, Zhu Y, Zhang S, Wei C, Hu B, et al. Diagnostic performance of the automated breast volume scanner: A systematic review of inter-rater reliability/agreement and meta-analysis of diagnostic accuracy for differentiating benign and malignant breast lesions. Eur Radiol. 2015 Dec; 25(12):3638-47.

\begin{tabular}{|c||l|l|}
\hline \multicolumn{3}{|c}{ AUTHORSHIP AND CONTRIBUTION DECLARATION } \\
\hline Sr. \# & \multicolumn{1}{|c|}{ Author(s) Full Name } & \multicolumn{1}{|c|}{ Contribution to the paper } \\
\hline 1 & Ishrat Parveen & $\begin{array}{l}\text { Principal Author, Proposed } \\
\text { topic, Basic study design. } \\
\text { Co-Author, Quality insurer. }\end{array}$ \\
\hline 2 & Koukab Javed & $\begin{array}{l}\text { Co-Author Methodology and } \\
\text { manuscript writing. } \\
\text { Co-Author-Data collection. }\end{array}$ \\
\hline 5 & Breeha Elahi & $\begin{array}{l}\text { Faran Nasrullah } \\
\text { Co-Author, Statistical analysis } \\
\text { \& interpretation of results. } \\
\text { Co-Author, Literature review, } \\
\text { Referencing. }\end{array}$ \\
\hline
\end{tabular}

